\title{
Synthesis of Substituted Isatins
}

\author{
Larry L. Klein ${ }^{*}$ and Michael D. Tufano \\ Institute for Tuberculosis Research, College of Pharmacy, University of Illinois at Chicago, $833 \mathrm{~S}$. \\ Wood Street, Chicago, Illinois-60612
}

\begin{abstract}
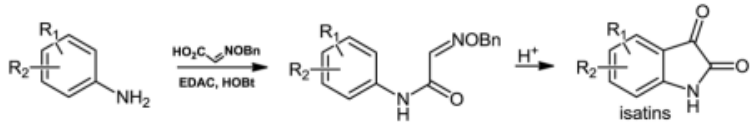

Isatins are valuable intermediates for heterocyclic chemistry. Most of the common methods for their production are less than adequate when the number and lipophilicity of substituents on the targeted isatin are increased. Our group desired such molecules and identified an alternative method for their production.
\end{abstract}

\section{Keywords}

isatin; Sandmeyer isatin synthesis; oximinoacetanilides

Isatins (1H-indole-2,3-diones, $\mathbf{1}$ ) are valuable intermediates in the field of heterocyclic and pharmaceutical chemistry [1]. Several of these derivatives show activities of biological interest [2] but most serve as templates in the construction of pharmaceutically active agents. Recently, we required multiply substituted isatins as intermediates and found the standard methods for their preparation to be less than optimal on a gram scale [3].

The most common procedure for the synthesis of isatins is the Sandmeyer process [4] which utilizes a mixture of chloral hydrate, an aniline (or its hydrochloride salt), hydroxylamine, and hydrochloric acid in a heated sodium sulfate-saturated aqueous media (Figure 1). The molecular mechanism for this process is believed to proceed through an initial glyoxamide 4 which reacts, in turn, with hydroxylamine to form the oximinoacetanilide, 5 [5a,b]. Heating compound $\mathbf{5}$ to $90{ }^{\circ} \mathrm{C}$ in sulfuric acid affects the ring cyclization to produce the isatin, $\mathbf{1}$.

Although this process has worked for simple analogs (Figure 1, 2a), as the substitution of the precursor anilines increases both in number and lipophilicity, the facility of this classical reaction to form the oximinoacetanilide intermediate 5 suffers. For example, when 4-nhexylaniline (2b) was used as starting material, $<5 \%$ yield of intermediate $\mathbf{5 b}$ could be isolated. Attempts to modify this process through the use of co-solvents such as ethanol [6a] or microwave heating [6b] have helped obtain some products not otherwise available, albeit

\section{(c) 2012 Elsevier Ltd. All rights reserved.}

*Larry L. Klein, Research Professor, Institute for Tuberculosis Research, College of Pharmacy, University of Illinois at Chicago, 833 S. Wood Street, Chicago, IL 60612, Ph: 312-413-9440, 1lk@uic.edu, fax: 312-355-5539.

Publisher's Disclaimer: This is a PDF file of an unedited manuscript that has been accepted for publication. As a service to our customers we are providing this early version of the manuscript. The manuscript will undergo copyediting, typesetting, and review of the resulting proof before it is published in its final citable form. Please note that during the production process errors may be discovered which could affect the content, and all legal disclaimers that apply to the journal pertain. 
in moderate yields. The fact that the key reagent, chloral hydrate, is a regulated substance also impacts the potential to perform large scale production of the isatins.

An alternative method for production of intermediate 5 or its equivalent was envisioned involving a coupling reaction of an alkyloximinoacetic acid $\mathbf{6}$ (Figure 2) and an aniline under standard amide-forming conditions; however, though hydroxyiminoacetic acid (6a) is known [7], reaction of this compound with anilines failed to provide product 5 . Crystalline benzyloximinoacetic acid (6b) is available in multi-gram quantities via an extractive workup following combination of $O$-benzylhydroxylamine and glyoxylic acid hydrate [8]. Coupling of $\mathbf{6 b}$ to a variety of substituted anilines led to good yields of the benzyoximinoacetanilides, $\mathbf{7}$ as shown in Table 1. The corresponding benzyloximinoacetyl chloride (8) is also available via treatment of $\mathbf{6} \mathbf{b}$ with oxalyl chloride and serves equally well to produce substituted anilines $\mathbf{7}$ in the presence of bases such as triethylamine or diisopropylethylamine in common organic solvents (e.g. dichloromethane, tetrahydrofuran).

It has been suggested that the ring cyclization step in the Sandmeyer process involves a dehydration of the oxime to form the a-acylnitrile (Figure 1). In the case of the benzyl analog, rather than loss of water, the loss of benzyl alcohol would have to take place to form this same reactive intermediate. When $\mathbf{7 a}$ was treated in this manner, the isatin product was formed in a similar yield as for the unsubstituted oximinoacetanilide, 5. Since no chemical trace of the benzyl residue was apparent from this modified reaction, it is presumed that any such alkyl moiety can be used in this approach. This reaction sequence was carried out at a ten gram scale without change in the yield of isatin 9 produced (Table 2, entry 1).

When oximinoacetanilide analogs of high lipophilicity (eg. 7f-h) were heated in sulfuric acid as per the classical Sandmeyer route, cyclization was frequently incomplete due to the poor solubility under these conditions. Use of methanesulfonic acid [9] as the media with these three oximinoacetanilides proved to be helpful in circumventing the problems and served to provide the corresponding isatin products even when little or no product was available from the sulfuric acid method (Table 2). In general, yields of isatins were similar or slightly improved when methanesulfonic acid was used as the media.

In the case of the extremely insoluble aryl-containing examples such as $\mathbf{7 p}$, although heating in methanesulfonic acid produced isatins, uncharacterized impurities arising from the process were difficult to remove. The preparation of 5-tritylisatin (16) from 4-tritylaniline was chosen as the most difficult example for method modification. In order to further increase solubility in the acidic media and avoid these impurities, two modifications were employed: 1) the corresponding methyloximinoacetanilide, 15, was utilized which was, in turn, prepared from acid 6c [10](Figure 3), and 2) polyphosphoric acid (PPA) was used as the media. In this way, 5-tritylisatin (16) was produced in $67 \%$ yield.

The straightforward preparation of benzyl-, or in certain cases methyloximinoacetanilides (such as $\mathbf{7 a - p , 1 5 )}$ and the heating of these intermediates in sulfuric acid, methanesulfonic acid, or, for poorly soluble analogs PPA, has been shown to afford substituted isatins. This modified aniline-to-isatin route circumvents many of the problems present in the classical Sandmeyer isatin synthesis and allows production of these substituted isatins in a reproducible manner.

\section{Supplementary Material}

Refer to Web version on PubMed Central for supplementary material. 


\section{References}

1. Shvekhgeimer MGA. Chem Heterocycl Compd. 1996; 32:249.

2. McIntyre IM, Norman TR. Serotonergic effects of isatin: An endogenous MAO inhibitor related to tribulin. J Neural Transm. 1990; 79:35-40.Dharmarajan S, Perumal Y, Gayatri G. Synthesis, antiHIV and antitubercular activities of lamivudine prodrugs. European J of Medicinal Chemistry. 2005; 40:1373-1376.

3. daSilva JFM, Garden SJ, Pinto AC. The Chemistry of Isatins: a Review from 1975-1999. J Braz Chem Soc. 2001; 12(3):273-324.

4. Sandmeyer T. Helv Chim Acta. 1919; 2:234.

5. 5a Marvel CS, Hiers GS. Isatin. Org Synthesis. 1941:327. Coll. Vol. 1. 5b Silva BV, Violante FA, Pinto AC, Santos LS. The mechanism of Sandmeyer's cyclization reaction by electrospray ionization mass spectrometry. Rapid Commun Mass Spectrom. 2011; 25:423-428. [PubMed: 21213361]

6. 6a Garden SJ, Torres JC, Ferriera AA, Silva RB, Pinto AC. Tetrahedron Lett. 1997; 38:1501.6b Jnaneshwara GK, Bedekar AV, Deshpande VH. Microwave Assisted Preparation of Isatins and Synthesis of ( \pm )-Convolutamydine-A. Synthetic Comm. 1999; 29(20):3627-3633.Mamun HM, Foysal MA, Mahabub M, Al-Amin. Microwave-assisted Efficient Synthesis of Isatins and spiroThiadiazolines under Green Chemistry Protocol. J Sci Res. 2010; 2(2):322-329.

7. Gutsche CD, Lau H-p. Association Phenomena. 3. Polyfunctional Catalysis of Acetyl Phosphate Decomposition. J Amer Chem Soc. 1978; 100(6):1857-1865.Other related couplings have been published: Waters KL, Hartung WH. J Org Chem. 1947; 12:469, 472. [PubMed: 20240591] Dong WL, Yao HW, Li ZM, Zhao WG. J of Chem Res, Synopses. 2008; 3:145- 147.Kalisiak J, Ralph EC, Cashman JR. J Med Chem. 2012; 55(1):465- 474. [PubMed: 22206546]

8. Herscheid JDM, Colstee JH, Ottenheijm HCJ. 1,4-Dihydroxy-2,5-dioxopiperazines from Activated N-Hydroxy Amino Acids. J Org Chem. 1981; 46:3346-3348.Kulkarni NA, Yao CF, Chen K. On the Scope of Diastereoselective Allylation of Various Chiral Glyoxylic Oxime Ethers with Allyltributylstannane in the Presence of a Lewis acid and Triallylaluminum. Tetrahedron. 2007; 63:7816-7822.

9. Rewcastle GW, Atwell GJ, Zhuang L, Baguley BC, Denny WA. Potential Antitumor Agents. 61. Structure-Activity Relationships for in Vivo Colon 38 Activity among Disubstituted 9-O O-9Hxanthene-4-acetic acids. J Med Chem. 1991; 34:217- 222. [PubMed: 1992120]

10. Lapucci A, Macchia M, Orlandini E, Romagnoli F, Rossello A. (E)-(Methyloximino)acetamides as Analogues of Neuroleptic Benzamides: Synthesis and D2-Dopaminergic Binding Affinity.

Farmaco. 1996; 51:33-40. [PubMed: 8721759] 
<smiles>[R]c1ccc(N)cc1</smiles>

a. $\mathbf{R}=\mathbf{H}$

3

b. $\mathbf{R}=\boldsymbol{n}$-hexyl<smiles>O=C1Nc2ccccc2C1=O</smiles>

isatin 1
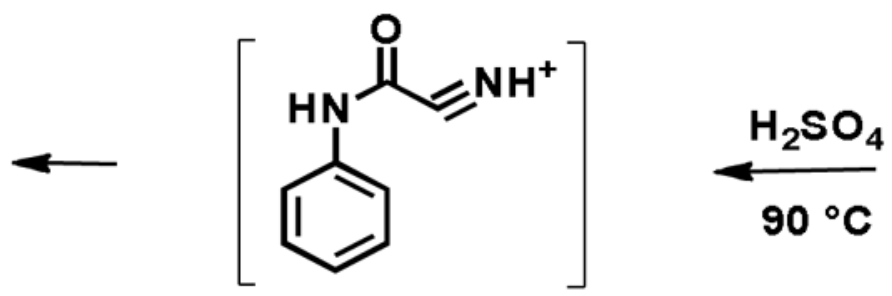
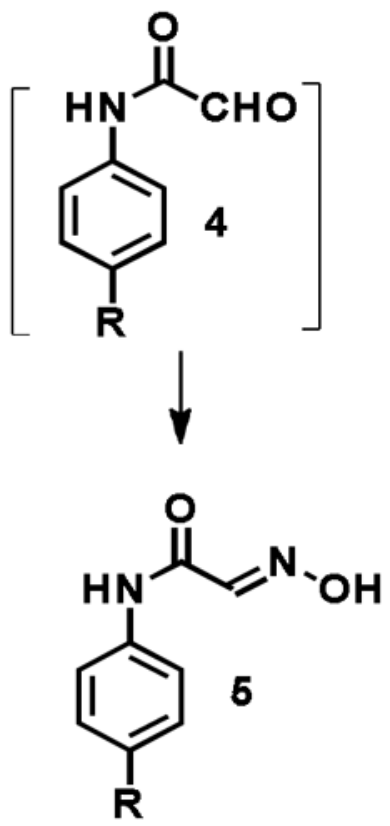

Figure 1.

Sandmeyer isatin process 


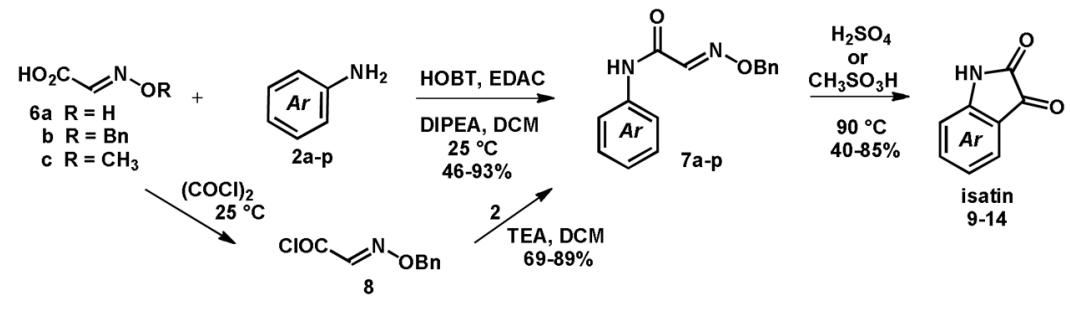

Figure 2.

Synthesis of alkyloximinoacetanilides 7. 

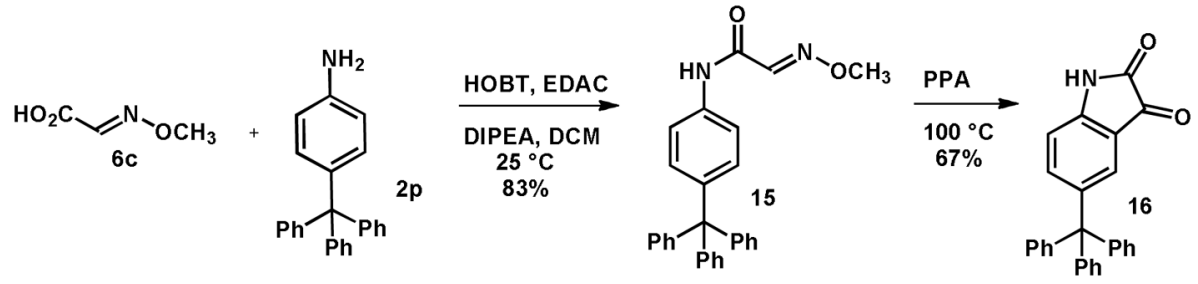

Figure 3.

Synthesis of 5-tritylisatin (16). 
Table 1

Preparation of benzyloximinoacetanilides.<smiles>N[14CH2][14CH2]NC(=O)/C=N\OCc1ccccc1</smiles>

\begin{tabular}{llllll}
\hline Entry & Product & Cpd \# Method $^{a}$ & Yield \% \\
\hline & NOBn & & & \\
\hline
\end{tabular}
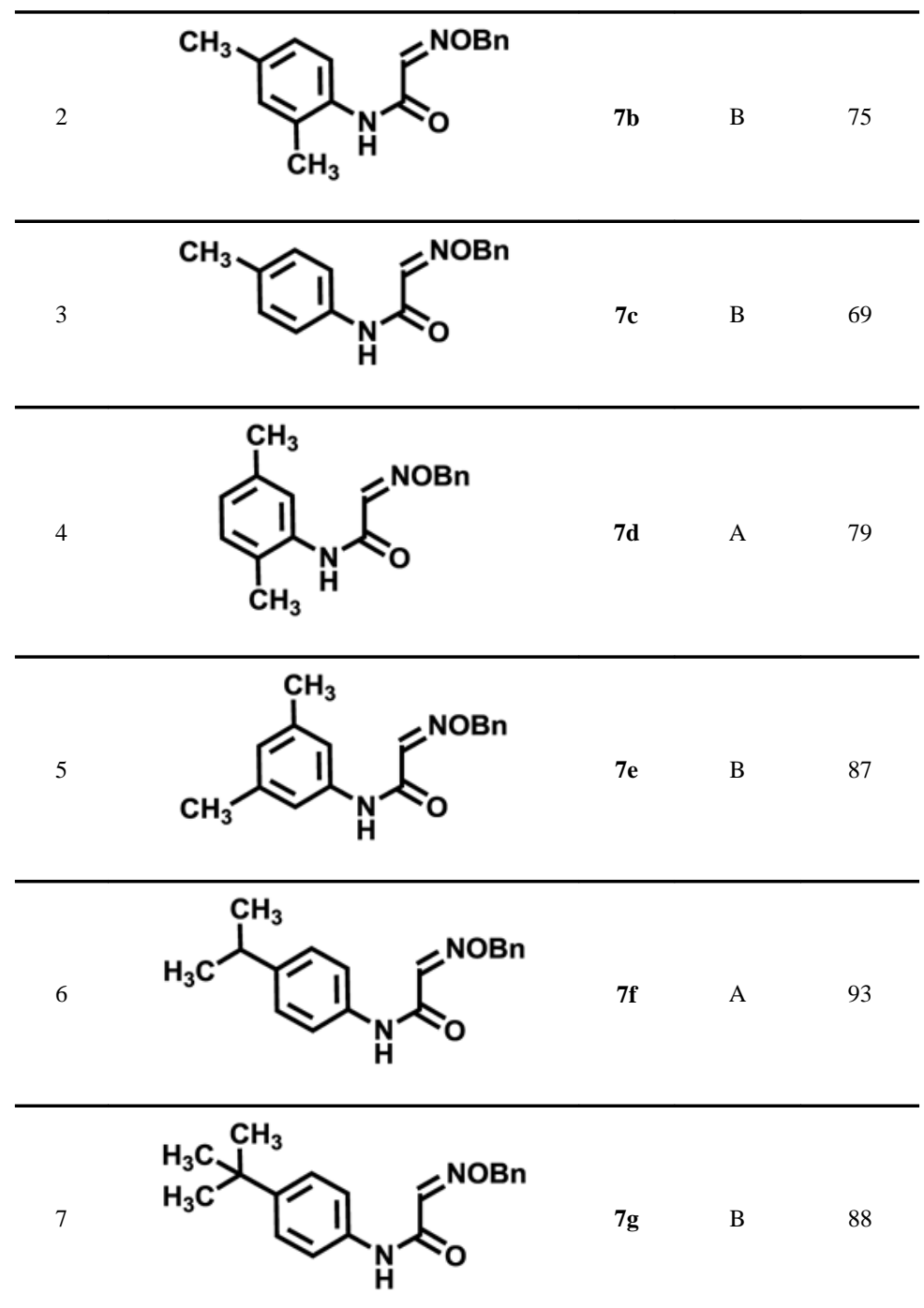
$\mathrm{Ar}_{\mathrm{NH}_{2}} \longrightarrow \mathrm{Ar} \mathrm{N}_{\mathrm{H}} \mathrm{N}_{\mathrm{O}}^{\mathrm{N}} \mathrm{O}_{\mathrm{O}}$
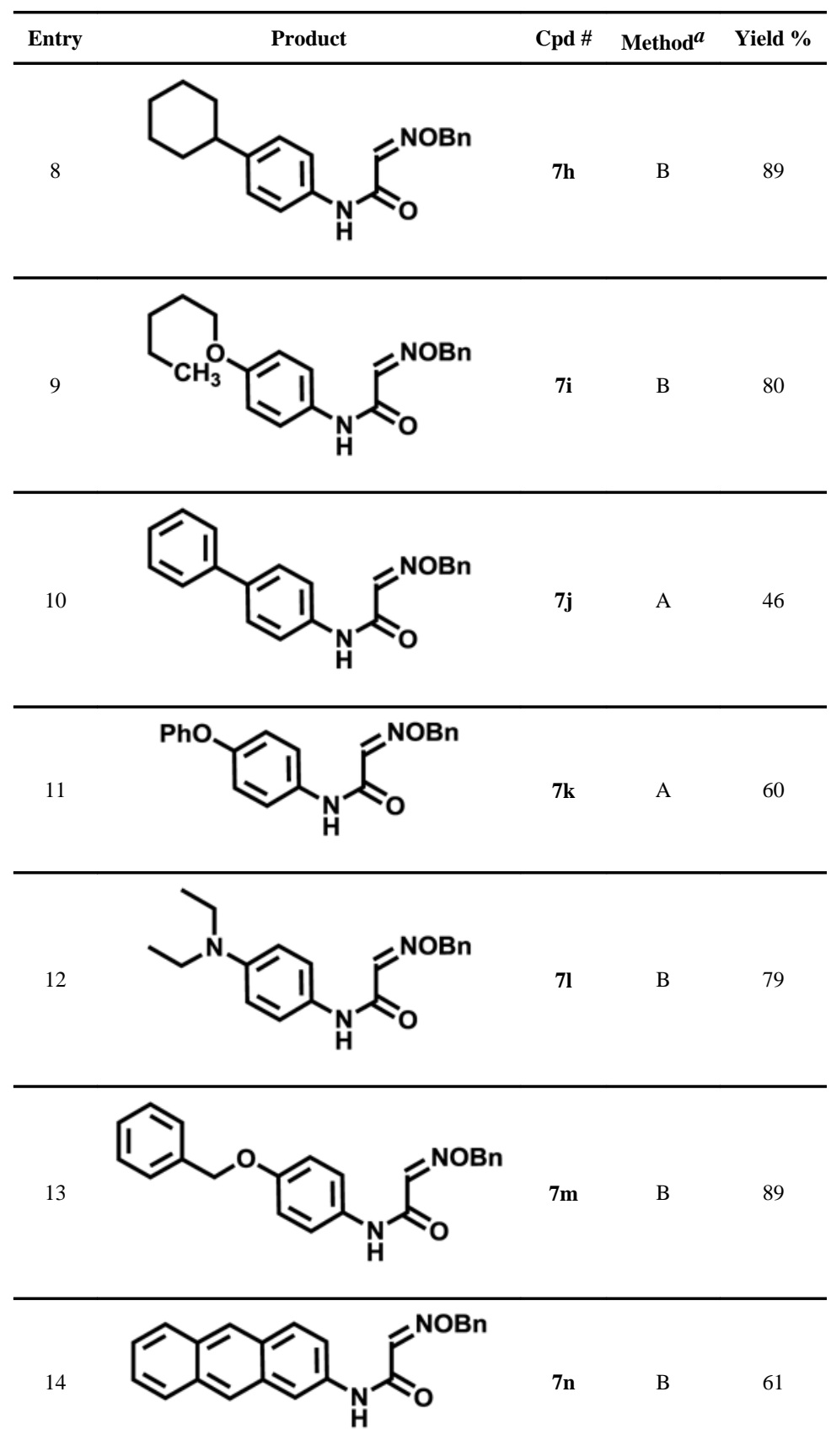

Tetrahedron Lett. Author manuscript; available in PMC 2014 February 01. 
<smiles></smiles>

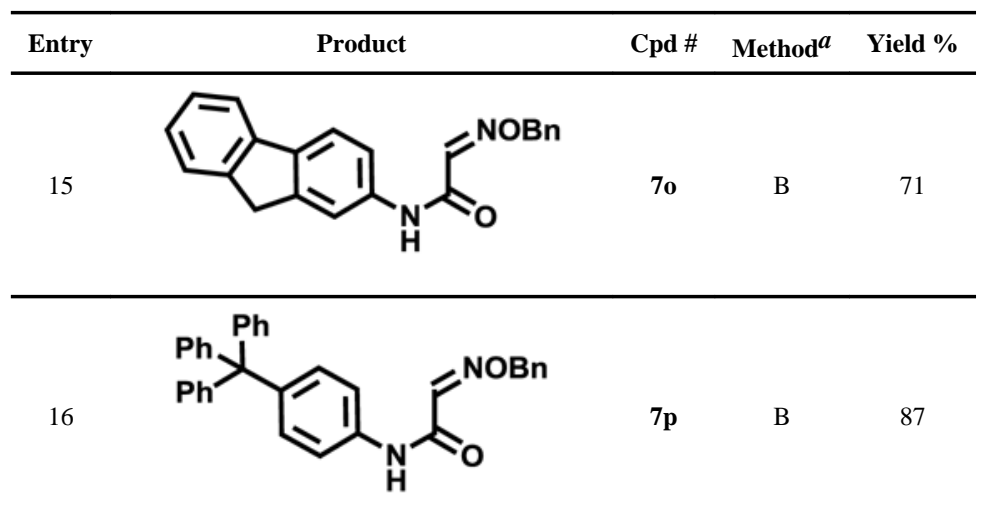

${ }^{a}$ Method A: $\mathrm{ArNH}_{2}, 1$ eq. $\mathrm{HO}_{2} \mathrm{CCH}=\mathrm{NOBn}, 1.5$ eq. EDAC, 1.5 eq. HOBt, 3 eq. DIPEA, THF, RT; or Method B: $\mathrm{ArNH}_{2}, 1.05$ eq. $\mathrm{ClCOCH}=\mathrm{NOBn}, 1.15$ eq. TEA, DCM, RT. 
Table 2

Preparation of isatins.

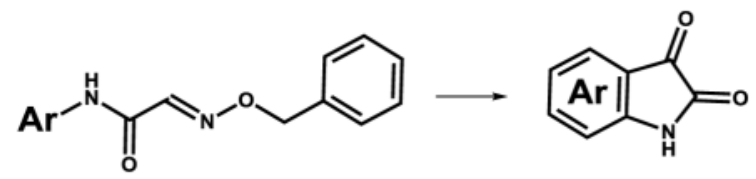

\begin{tabular}{llllll}
\hline Entry & Product & & Cpd \# & $\operatorname{Method}^{a}$ & Yield \% \\
\hline & & & & & \\
\end{tabular}
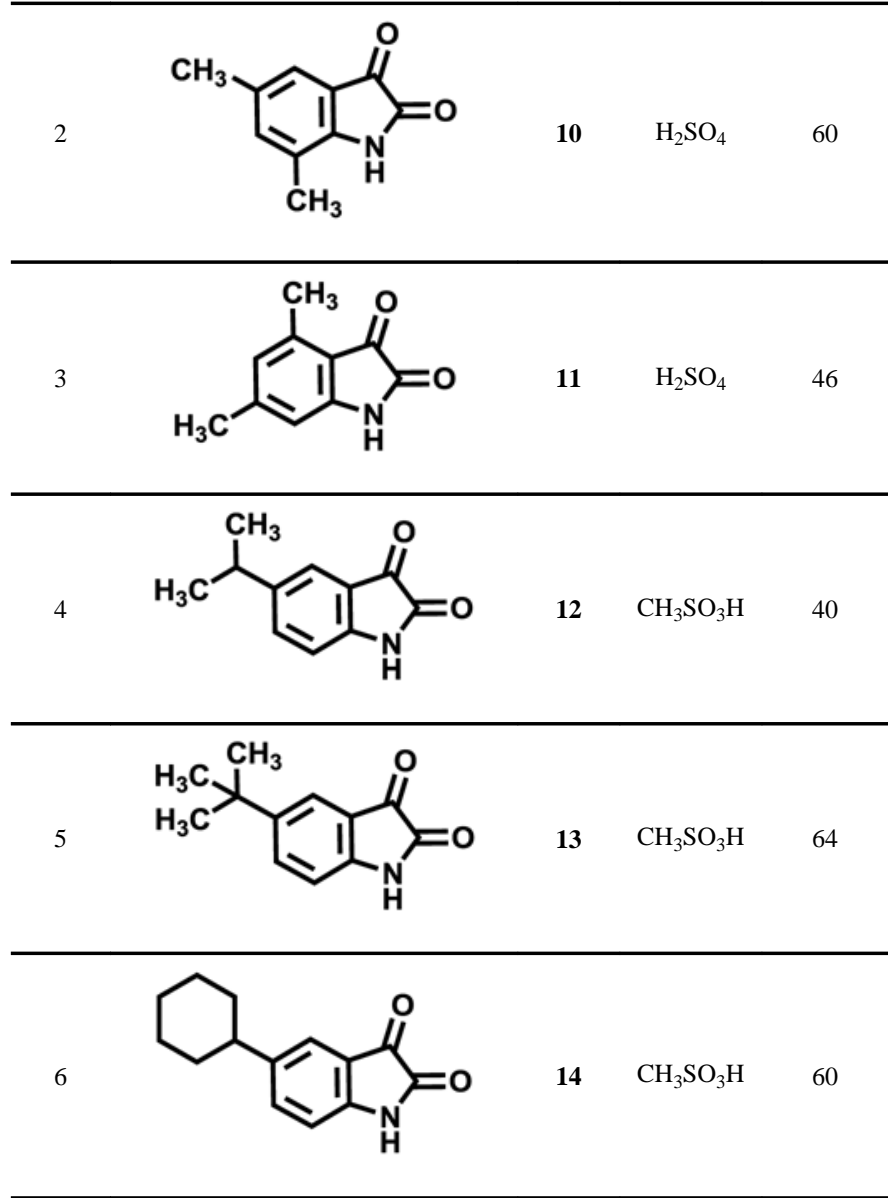

${ }^{a}$ Method A: $\mathrm{H}_{2} \mathrm{SO}_{4}$ at $50{ }^{\circ} \mathrm{C}$, heat to $80{ }^{\circ} \mathrm{C}$; add to ice; Method B: $\mathrm{CH}_{3} \mathrm{SO}_{3} \mathrm{H}$ at $50{ }^{\circ} \mathrm{C}$, heat to $80{ }^{\circ} \mathrm{C}$; add to ice. 